\title{
Electrochemical behavior of 1,2-dihydroxyanthraquinone dianion in aprotic solvents-DMSO and DMF: understanding the hydrogen bonding phenomena and protonation effect in biochemical systems
}

\author{
Muhammad Tariq ${ }^{1}$ (I) Inam Ullah ${ }^{1}$
}

Received: 11 February 2020 / Accepted: 6 April 2020 / Published online: 9 April 2020

(c) Springer Nature Switzerland AG 2020

\begin{abstract}
In this work, we report, the electrochemical properties of 1,2-dihydroxyanthraquinone through cyclic voltammetry (CV) and square wave voltammetry (SWV) in two aprotic solvents-DMSO and DMF. It is investigated that 1,2-dihydroxyanthraquinone undergoes two single-electron reduction processes. The first electron transfer process corresponds to formation of anion radical while the second electron transfer corresponds to dianion of 1,2-dihydroxyanthraquinone. Concentration effect and scan rate effect on CV of 1,2-dihydroxyanthraquinone is also studied. Effect of different alcohols (hydrogen-bonding agents) and organic acids (protonating agents) on the CVs and SWVs of 1,2-dihydroxyanthraquinone is also investigated. It is found that addition of alcohols shifts the peak potential of the dianion towards less negative potential whereas addition of organic acids) inhabits the formation of dianion. Furthermore, it is also observed that methanol has strong hydrogen-bonding interaction with 1,2-dihydroxyanthraquinone as compared to ethanol and propanol. The hydrogen bonding equilibrium constant and hydrogen-bonding rate constants are evaluated from the shift in CV curves using Gupta and Linchtiz equation. It is inferred that the anion radical has a very weak hydrogen bonding interaction with alcohols as compared to dianion.
\end{abstract}

Keywords Cyclic voltammetry · Quinones · Alcohols · Dianion · Square wave voltammetry

\section{Introduction}

Quinones-an organic compound have been studied for more than a century due to their versatile and unique properties [1-3]. Quinones compounds can undergo complex reversible redox reactions, which is responsible for electron transfer in biological system [1]. Natural quinones perform multiple functions in biological systems, extending from mechanisms of self-defense in insects to formation of bones in mammals $[2,3]$. Important function of quinones includes electron transfer and phosphorylation in living systems [4]. Its most vital role is electron transfer agent in metabolic processes like photosynthesis and respiration in human [5]. Therefore, interest of researchers increased towards the study of quinones, different research studies has been carried out on quinones and the redox potential of different quinones has been investigated in various aprotic and protic solvents [6]. Due to the redox behavior, quinones finds a wide range of applications in many fields [7-15].

For example, ubiquinones are a class of quinones present in all the living cells where its function is electron

Electronic supplementary material The online version of this article (https://doi.org/10.1007/s42452-020-2707-2) contains supplementary material, which is available to authorized users.

Muhammad Tariq, dr.muhammadtariq@uop.edu.pk; $₫$ Inam Ullah, inam392@gmail.com | ${ }^{1}$ National Centre of Excellence in Physical Chemistry, University of Peshawar, Peshawar 25120, Pakistan. 
transfer in cellular respiration $[7,8]$. These quinones containing compounds are also present in all respiring cells of living organisms where they develop important functions and act as components in cellular respiration and photosynthesis [9-11]. Investigations has showed that plastoquinone [12] is one of the major constituent of chloroplast in higher plants (plants of complex or advanced characteristics) besides plastoquinone some other types of quinones are also part of chloroplast these includes tocopherylquinones [13] and naphthoquinone (vitamin K) [14]. From the last few decades scientist was focused on the mechanism of action of quinones, it has been investigated that quinones occur usually in several fold in living systems. Metabolism is a chemical process that occur in all the respiring cells in order to maintain its life activities, an essential part of metabolism is the electron transfer reaction which is assisted by quinones in many biological systems, where oxygen accepts electron in the oxidation reaction and ATP is produced [15].

Also, quinone compounds have much importance in the field of biochemistry and medicinal chemistry [16] because compounds having quinone moiety play an important role in biological activities, these quinone containing compounds are also used as anti-tumor agents [17, 18], anti-malarial [19], anti-bacterial [20], antineoplastic [21], anticoagulant [22], fungicides [23] and herbicides [24]. Since, the biological activity of quinoid compounds is due to the redox behavior of quinone system $[9,16]$. Due to the redox behavior they can easily form hydrogen bond.

Hydrogen bonding is a type of intermolecular bond in which a hydrogen atom is bonded to a strong electronegative atom that is present near another electronegative atom which have lone pair of electrons. This bond is stronger than dipole-dipole but not stronger than ionic and covalent bonds.

Hydrogen bonding has been of great interest because it plays a key role in many chemical and biochemical systems such as structure stability of many biological molecules [25], molecular recognition [26] and intermolecular interactions in the DNA. Hydrogen bonding can play an important role in electron-transfer reactions and this remains to be a central part of investigation in electrochemistry. An important role of hydrogen bonding is to ease the protoncoupled electron transfer rations [27-30]. This is necessary for electron transfer in biological systems, but it also have importance in electrochemical energy production and consumption reactions. Hydrogen bonding can also affect kinetics of proton-coupled electron transfer reactions by forming network of hydrogen bonds [31]. It was appreciated in the past that intra-molecular hydrogen bonding and intermolecular hydrogen bonding can assist transfer of electron. Recently, studies has been further extended to the hydrogen bonding by adding guests [32, 33]. In recent years, different experimental and theoretical methods have been used to investigate the structure and dynamics of intermolecular hydrogen bonding [6].

Several techniques are used for measuring the $\mathrm{H}$-bonding interaction such as UV-visible spectroscopy and electrochemical techniques. The latter is more sensitive for $\mathrm{H}$-bonding interactions [34]. In electrochemistry especially cyclic voltammetry is used to measure the hydrogen bonding interaction, this is due to the electrostatic properties of hydrogen bonds [35].

The present study is focused on the electrochemistry of 1,2-dihydroxyanthraquinone, a derivative of quinone which is commonly known as alizarin which upon electrochemical reduction can form semi-quinones and hydroquinones through one and two-electron reduction. It occurs naturally in madder plant in the form of glucoside. It is a histochemical pigment used by the dermatologists for the detection of calcium and basic calcium phosphates in the field of medicine. It is also used as mediator for modifying glassy carbon and graphite electrodes for investigating the electrochemistry of hydrazine and determination of ultratrace copper [36]. In the field of medicine anthraquinones are used for the treatment of a variety of human cancer where its activities are because of the redox behavior [37]. Therefore, it is necessary to study the reaction pathways and the factors which control the potentials of various species which appear in quinone-hydroquinones in biological system. Interest of researchers also increased towards the study of electrochemical properties of quinones such as its stability and reactivity of the electro generated reduced species produced as a result of quinone electro-reduction [38].

1,2-dihydroxyanthraquinone has two hydroxyl groups which are attached to a benzene ring at two different positions (Fig. 1). As quinones have oxygen which have lone pair of electrons in their oxidized form, consequently, they can form $\mathrm{H}$-bond with molecules having hydrogen atom attached to oxygen i.e. protic molecules.

Hence, in the present study it is intended to investigate the hydrogen bonding interaction, the kinetic and equilibrium constant of the dianion of

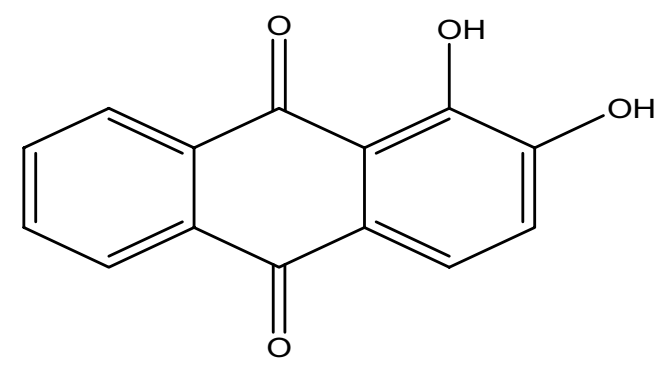

Fig. 1 Structure of 1,2-dihydroxyanthraquinone 
1,2-dihydroxyanthraquinone with different hydrogen bonding agents in nonaqueous solvents. The effect of different solvents on the kinetics and equilibrium constant of 1,2-dihydroxyanthraquinone. Electrochemical techniques cyclic voltammetry and square wave voltammetry will be used for the measurement of hydrogen bonding interaction.

\section{Experimental}

\subsection{Materials}

1,2-dihydroxyanthraquinone $\left(\mathrm{C}_{14} \mathrm{H}_{8} \mathrm{O}_{4}, \geq 95 \%\right)$ and 2-propanol $\left(\mathrm{C}_{3} \mathrm{H}_{8} \mathrm{O}\right.$, extra pure) were purchased from $\mathrm{BDH}$ Chemicals Ltd Poole England. N, N-Dimethylformamide $\left(\mathrm{C}_{3} \mathrm{H}_{7} \mathrm{NO}, 99 \%\right)$ was obtained from Sigma Aldrich. Dimethyl sulfoxide $\left(\mathrm{C}_{2} \mathrm{H}_{6} \mathrm{OS}\right.$, extra pure), methanol $\left(\mathrm{CH}_{3} \mathrm{OH}, 99.9 \%\right)$ and ethanol $\left(\mathrm{C}_{2} \mathrm{H}_{6}, 99.9 \%\right)$ were purchased from Scharlau. Acetic acid $\left(\mathrm{CH}_{3} \mathrm{COOH}, 99.5 \%\right)$ and Lithium per chlorate $\left(\mathrm{LiClO}_{4}\right)$ were purchased from Acros Organics and ascorbic acid $\left(\mathrm{C}_{6} \mathrm{H}_{8} \mathrm{O}_{6}\right)$ from Merck. All these chemicals were used as received and no further purification was done. Highly pure argon gas was use for purging the solution. All chemicals were HPLC/analytical-grade. The solvents acetonitrile and DMF was dried over $4 \AA$ molecular sieve and further passed through an alumina column. Similarly, methanol $(\mathrm{MeOH})$, ethanol $(\mathrm{EtOH})$, and 2-propanol $(\mathrm{PrOH})$ were all HPLC/analytical-grade and dried over 3 Å molecular sieve.

\subsection{Instrumentation}

Electrochemical studies were performed using Digi-Ivy (DY2113) Potentiostat. A Glassy carbon electrode having $3 \mathrm{~mm}$ diameter were used as working electrode, while silver/silver chloride $(\mathrm{Ag} / \mathrm{AgCl}$, saturated $\mathrm{KCl})$ and custommade gold electrode were used as reference electrode as counter electrode, respectively.

\subsection{Electrochemical measurements}

All the experiments were performed using a threeelectrode cell fitted with working, counter and reference electrodes. A $20 \mathrm{ml}$ solution of 1, 2-dihydroxyanthraquinone ( $3 \mathrm{mM}$ ) in $0.1 \mathrm{M} \mathrm{LiClO}_{4}$ (as supporting electrolyte) in DMSO/DMF (as solvent) was taken in the cell during all the experiments. The glassy carbon electrode (working electrode) was polished with the slurry of alumina powder, then sonicated and finally rinsed with distilled water for each measurement. The solution was purged with high pure argon gas. Cyclic voltammetry and square wave voltammetry were recorded both in the absence and presence of various concentration of hydrogen bonding agent. All the experiments were performed at room temperature and at a moderate scan rate $(50-100 \mathrm{mV} / \mathrm{s})$. Exceptionally, scan rate study were performed at high scan rate. Data were transferred and stored in a computer and then retrieved.

\section{Results and discussion}

\subsection{Cyclic Voltammetry 1,2-dihyidroxyanthraquinone in DMSO and DMF}

CVs of $3 \mathrm{mM} 1,2$-dihydroxyanthraquinone in $0.1 \mathrm{M} \mathrm{LiClO}_{4}$ were recorded at moderate scan rate (i.e. $100 \mathrm{mV} / \mathrm{s}$ ) versus silver/silver chloride reference electrode using GCE as working electrode in DMSO and DMF. It was noted that GCE gives no response in the absence of 1,2-dihydroxyanthraquinone (blank) under argon atmosphere whereas addition of analyte (1,2-dihydroxyanthraquinone) gives CV response in the potential range from 0 to $-1.5 \mathrm{~V}$ (Fig. 2). It was observed that 1,2-dihydroxyanthraquinone gives two reduction peaks in both the aprotic solvents. First peak was attributed for formation of radical anion and the second peak was assigned to the formation of dianion. Almost same peak potentials were observed in both solvents however, a high peaks current was recorded in DMF (as compared to DMSO) for the same concentration of 1,2-dihydroxyanthraquinone because of the high diffusion coefficient of 1,2-dihydroxy anthraquinone in DMF. Besides the two major reduction peaks, shoulder peaks were also present in both reduction and oxidation scans [4]. Since, the present study is mainly concerned with hydrogen bonding, which is reportedly to be formed with the dianion of quinones [39]. Therefore, the shift in the second peak will (that peak i.e. $I_{c}$ ) monitored which represent the strength of hydrogen bonding was further studied (see Sect. 3.2).

\subsubsection{Concentration effect of CV}

To check concentration effect of 1,2-dihydroxyanthraquinone on GCE cyclic voltammograms were recorded in $0.1 \mathrm{M} \mathrm{LiClO}_{4}$ in DMSO and DMF at a scan rate of $100 \mathrm{mV} / \mathrm{s}$. Upon increasing the concentration of 1,2-dihydroxyanthraquinone, the peak current also increases, it shows that electrochemical activity on GCE is dependent on the concentration of 1,2-dihydroxyanthraquinone in both DMSO and DMF (Fig. 3). Analysis of the peak height shows a linear response with the regression constant value $\left(R^{2}\right)$ of 0.991 (inset of Fig. 3). 

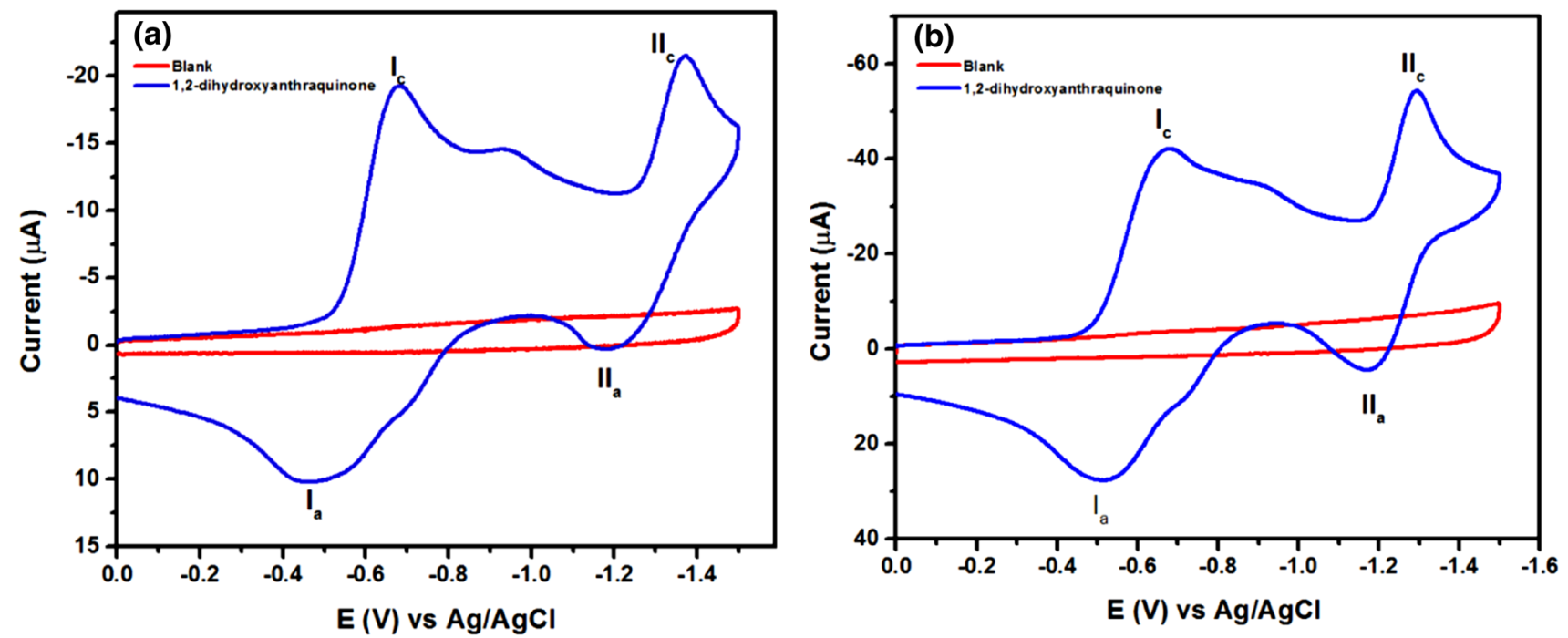

Fig. 2 CVs of $3 \mathrm{mM} \mathrm{1,2-dihydroxyanthraquinone} \mathrm{in} 0.1 \mathrm{M} \mathrm{LiClO} 4$ at Scan rate of $100 \mathrm{mV} / \mathrm{s}$ in a DMSO and in b DMF
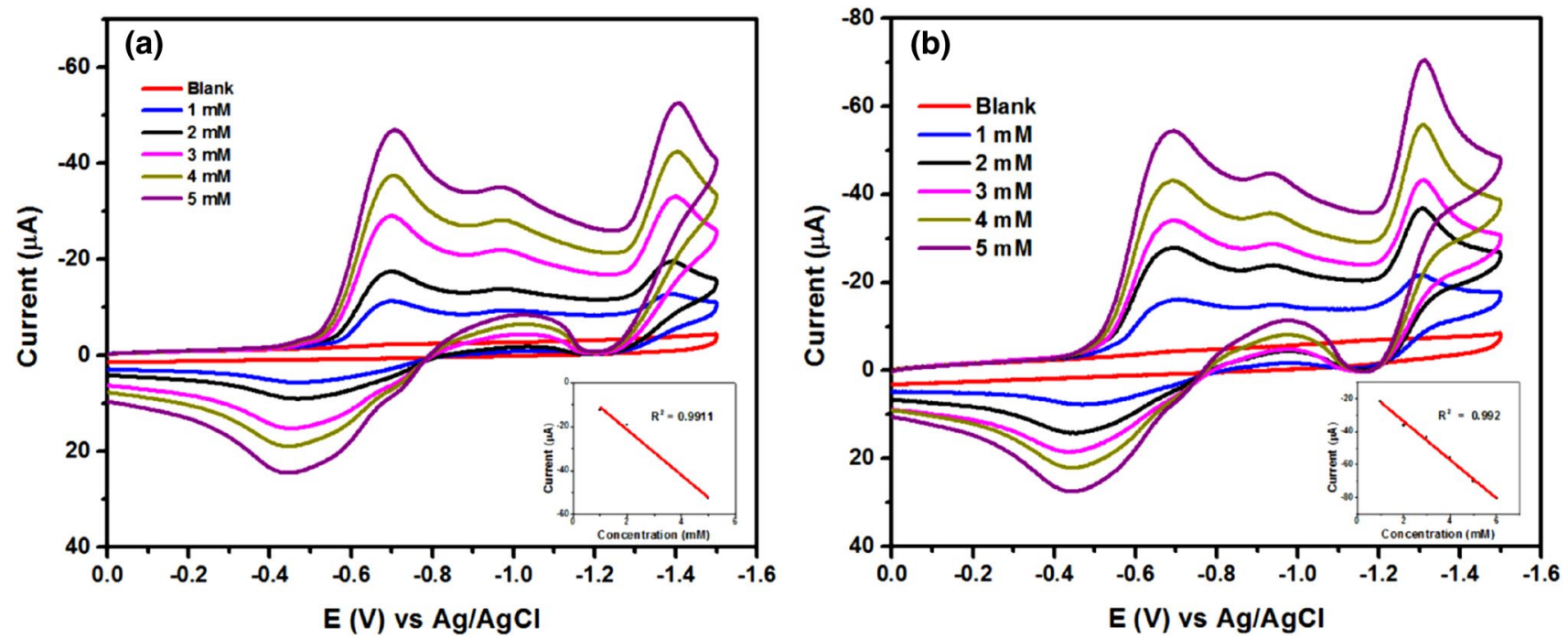

Fig. 3 Effect of Concentration on the CV of 1,2-dihydroxyanthraquinone on GCE in $0.1 \mathrm{M} \mathrm{LiClO4}$ at Scan rate of $100 \mathrm{mV} / \mathrm{s}$ a DMSO and $\mathbf{b}$ DMF

\subsubsection{Scan rate effect of CV}

Scan rate provides information about the electrochemical properties of species that are generated at the surface of electrode. Therefore, effect of scan rate on the electrochemical properties of 1,2-dihydroxyanthraquinone was investigated. Scan rate effect was studied in the rage from 10 to $200 \mathrm{mV} / \mathrm{s}$. CVs shows that upon increasing scan rate, the peak current $\left(I_{p}\right)$ increases whereas peak potential remains unaffected as shown in Fig. 4. By plotting the graph of $I_{p}$ versus square root of scan rate a linear graph is obtained, which indicates that the system is diffusion controlled (insert Fig. 4a).

\subsection{CV of 1,2-dihydroxyanthraquinone in the presence of alcohols: effect of hydrogen bonding agents}

\subsubsection{Effect of methanol}

Upon addition of various concentration of in 1,2-dihydroxyanthraquinone solutions, it was observed that 

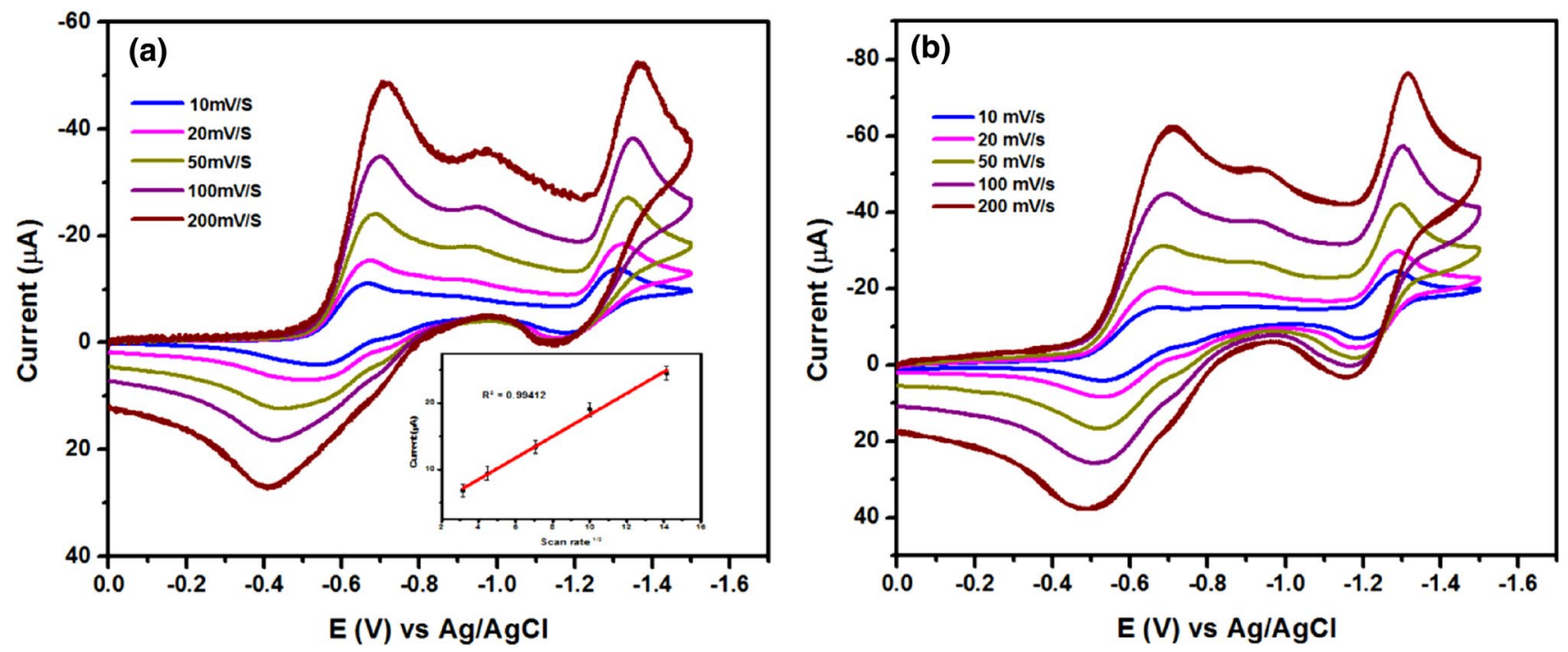

Fig. 4 CVs of $3 \mathrm{mM} \mathrm{1,2-dihydroxyanthraquinone} \mathrm{on} \mathrm{GCE} \mathrm{in} 0.1 \mathrm{M} \mathrm{LiClO}_{4}$ at various scan rate in a DMSO (inset Peak current vs. Square. root of Scan rate), b DMF

second reduction peak potential shift toward positive side/ less negative side. The shift in peak potential were continuously occur with methanol concentration (Fig. 5). This shift in peak potential towards less negative side was due to methanol-quinone interaction i.e. hydrogen-bonding.

\subsubsection{Effect of ethanol}

In case of ethanol, similar results were obtained (as observed in case of methanol) i.e. shift in peak potential towards less negative confirming the formation of hydrogen bonds shown in Supplementary material (Figs. $\mathrm{S} 1, \mathrm{~S} 2)$. However, in this case, the shift was less than that of methanol's addition this may be due the fact that the hydroxy group on ethanol is barely more shielded than on methanol hence the formation of hydrogen bonds is hindered.

\subsubsection{Effect of propanol}

Addition of propanol also results a shift in peak potential, but as propanol has more bulky structure than methanol
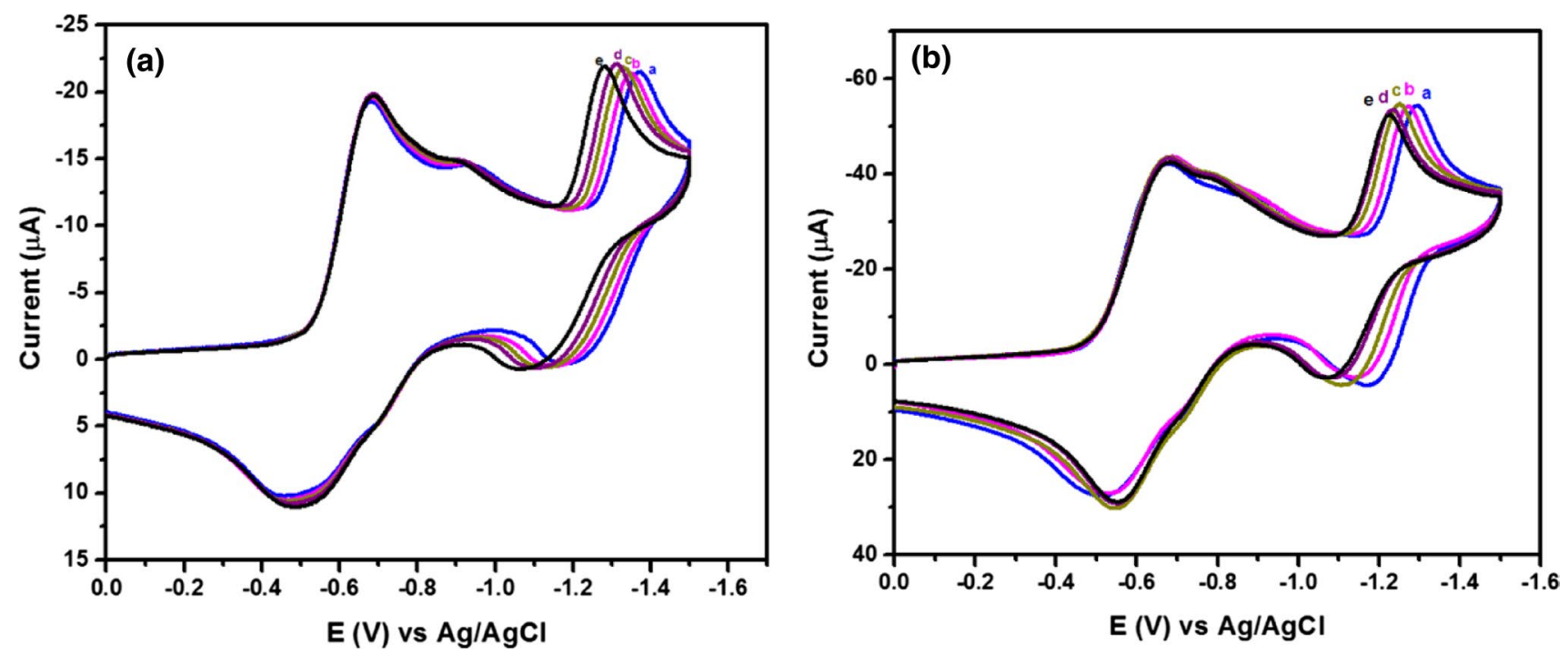

Fig. 5 CVs of $3 \mathrm{mM}$ 1,2-dihydroxyanthraquinone in $0.1 \mathrm{M} \mathrm{LiClO}_{4}$ with different concentration of methanol (a) $0 \mathrm{M}$, (b) $0.24 \mathrm{M}$, (c) $0.56 \mathrm{M}$, (d) $1.24 \mathrm{M}$ and (e) $1.84 \mathrm{M}$ in two aprotic solvents-DMSO (a) and DMF (b) 
and ethanol therefore the shift occur due to addition of propanol is much smaller as compared to ethanol and methanol (Supplementary material Figs. S3, S4). In this case the current also decreases with the addition of each concentration of propanol this because of the dilution of the solution with the addition of propanol.

\subsection{Quantitative treatment of intermolecular hydrogen bonding}

The following reaction scheme is adopted as given by previous workers [39-41].

$\mathrm{AQ}+\mathrm{e} \rightleftharpoons \mathrm{AQ}^{-}$

$\mathrm{AQ}^{-\cdot}+\mathrm{nHB} \rightleftharpoons \mathrm{AQ}^{-\cdot}(\mathrm{HB})_{\mathrm{n}}$

$\mathrm{AQ}^{-\cdot}(\mathrm{HB})_{\mathrm{n}}+\mathrm{e} \rightleftharpoons \mathrm{AQ}^{2-}(\mathrm{HB})_{\mathrm{n}}$

$\mathrm{AQ}^{2-}(\mathrm{HB})_{\mathrm{n}}+(\mathrm{m}-\mathrm{n}) \mathrm{HB} \rightleftharpoons \mathrm{AQ}^{2-}(\mathrm{HB})_{\mathrm{m}}$

where $A Q$ is the 1,2-dihydroxyanthraquinone, $A^{--}$is the anion radical, and $\mathrm{AQ}^{2-}$ dianion; $\mathrm{HB}$, is hydrogen bonding agent (alcohol).

The corresponding linear equation for reduction, as given by Gupta and Linschitz [39]

$\mathrm{E}_{1 / 2}^{\prime}=\mathrm{E}_{1 / 2}+\mathrm{RT} / \mathrm{F} \ln \left(1+\mathrm{K}_{\mathrm{eq}}\right)[\mathrm{HB}]^{\mathrm{n}}$

where $E_{1 / 2}^{\prime}$ is the potential of half wave in the presence of $H B$ and $E_{1 / 2}$ is the potential of half wave in the absence of
$\mathrm{HB}$. An equilibrium constant, $\mathrm{K}_{\mathrm{eq}}^{(1)-}$ for the first reduction step can be written as,

$\Delta \mathrm{E}_{1 / 2}=\mathrm{n}(\mathrm{RT} / \mathrm{F}) \ln [$ alcohol $]+(\mathrm{RT} / \mathrm{F}) \ln \mathrm{K}_{\text {eq }}^{(1)}$

If $\mathrm{K}_{\text {eq }}^{(1)}$ [alcohol] is ${ }^{\text {>> }} 1$, then a graph between $\Delta \mathrm{E}_{1 / 2}$ versus $\ln [$ alcohol] should give straight line with slope $2.3 \mathrm{nRT} / \mathrm{f}$, hence the value of $\mathrm{n}$ can estimated from slope.

To obtained the value of equilibrium constant, $\mathrm{K}_{\mathrm{eq}}^{(1)-}$ for first reduction step, Eq. (5) to obtain

$\exp \left(f \Delta \mathrm{E}_{1 / 2}\right)=1+\mathrm{K}_{\text {eq }}^{(1)}[\text { alcohol }]^{\mathrm{n}}$

where $f=\mathrm{F} / \mathrm{RT}$ and $\Delta \mathrm{E}_{1 / 2}=\mathrm{E}_{1 / 2}^{\prime}+\mathrm{E}_{1 / 2}$.

Similarly, the equilibrium constant of second reduction step for hydrogen bonding, we have

$\exp \left(f \Delta \mathrm{E}_{1 / 2}\right)=\frac{1+\mathrm{K}_{\text {eq }}^{(2)}[\text { alcohol }]^{\mathrm{m}}}{1+\mathrm{K}_{\text {eq }}^{(1)}[\text { alcohol }]^{\mathrm{n}}}$

where $\mathrm{m}$ is the number of hydrogen bonded to $\mathrm{Q}^{2-}$ and $\mathrm{k}_{\mathrm{eq}}^{(2)}$ is the corresponding equilibrium constant. If the hydrogen bonding is strong then 1 is neglected in the numerator and denominator, so $m-n$ value could be obtained by plotting $E_{1 / 2}$ versus In [alcohol] for second reduction step (Fig. 6). The values of $E_{1 / 2}, E_{1 / 2}^{\prime}, \Delta E$, and $E_{p}$ deduce from $C V s$ of 1,2-dihydroxyanthraquinone in the presence and absence of hydrogen bonding agents (HB), for utilizing in the above equations are collected in Table 1.

Having values of $k_{\mathrm{eq}}^{(1)} \mathrm{m}$ and $\mathrm{n}$ then $\mathrm{k}_{\mathrm{eq}}^{(2)}$ can be calculated from Eq. (8) as given in Table 2. However, in the table, values of $n$ and $k_{e q}^{(1)}$ are not determined because no change in peak potential occurs in first reduction step with the
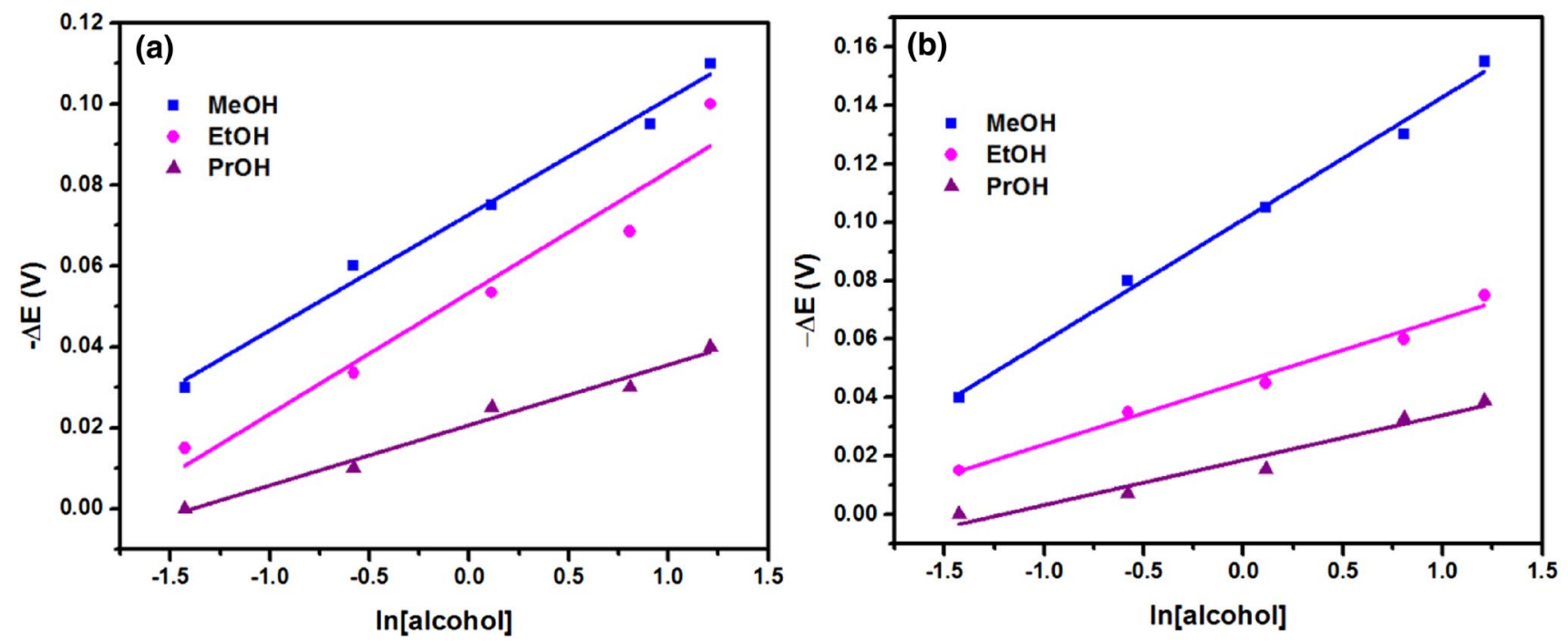

Fig. 6 Plot of $\Delta \mathrm{E}_{1 / 2}$ versus In[alcohol] in a DMSO, and in $\mathbf{b} \mathrm{DMF}$ 
Table 1 Electrochemical parameters for hydrogen bonding $(\mathrm{HB})$ of anion radical of 1,2-dihydroxyanthraquinone in DMSO

\begin{tabular}{|c|c|c|c|c|c|c|c|c|c|}
\hline \multirow[t]{2}{*}{ Solvent } & $\begin{array}{l}\text { HB agent } \\
\text { conc. (M) }\end{array}$ & $-E_{1 / 2}^{\prime}(V)$ & -Ep (V) & $\begin{array}{l}\text { HB agent } \\
\text { conc. (M) }\end{array}$ & $-E_{1 / 2}^{\prime}(V)$ & $-E_{p}(V)$ & $\begin{array}{l}\text { HB agent } \\
\text { conc. (M) }\end{array}$ & $-E_{1 / 2}^{\prime}(V)$ & $-E_{p}(V)$ \\
\hline & \multicolumn{3}{|c|}{ HB agent: methanol } & \multicolumn{3}{|c|}{ HB agent: ethanol } & \multicolumn{3}{|c|}{ HB agent: 2-propanol } \\
\hline \multirow[t]{5}{*}{ DMSO } & 0.00 & - & 1.37 & 0.00 & - & 1.4 & 0.00 & - & 1.40 \\
\hline & 0.56 & 1.84 & 1.35 & 0.56 & 1.89 & 1.38 & 1.20 & 1.90 & 1.38 \\
\hline & 1.20 & 1.82 & 1.33 & 1.20 & 1.85 & 1.36 & 1.84 & 1.89 & 1.37 \\
\hline & 1.84 & 1.77 & 1.31 & 2.48 & 1.82 & 1.33 & 2.48 & 1.86 & 1.35 \\
\hline & 2.48 & 1.70 & 1.28 & 3.76 & 1.66 & 1.30 & 3.76 & 1.84 & 1.34 \\
\hline \multirow[t]{6}{*}{ DMF } & 0.00 & - & 1.29 & 0.00 & - & 1.32 & 0.00 & - & 1.30 \\
\hline & 1.12 & 1.78 & 1.27 & 0.24 & 1.84 & 1.31 & 0.16 & 1.83 & 1.29 \\
\hline & 2.24 & 1.75 & 1.25 & 0.56 & 1.82 & 1.29 & 0.24 & 1.83 & 1.29 \\
\hline & 2.80 & 1.72 & 1.24 & 0.88 & 1.80 & 1.29 & 0.56 & 1.82 & 1.28 \\
\hline & 3.36 & 1.7 & 1.23 & 1.20 & 1.79 & 1.28 & 2.24 & 1.80 & 1.28 \\
\hline & 3.92 & 1.67 & 1.22 & 1.76 & 1.77 & 1.27 & 3.36 & 2.43 & 1.28 \\
\hline
\end{tabular}

Table 2 Hydrogen bonding equilibrium constant $\mathrm{K}_{\mathrm{eq}}$ for 1,2-dihydroxyanthraquinone anion radical with $\mathrm{MeOH}$., $\mathrm{EtOH}$ and 2-PrOH in DMSO and DMF

\begin{tabular}{lllll}
\hline S. no. & HB agent & Solvents & $\mathrm{k}_{\text {eq }}^{(2)}(\mathrm{M})$ & $\mathrm{m}$ \\
\hline 1. & Methanol & DMSO & 50.9 & 1.63 \\
& & DMF & 16.9 & 1.15 \\
2. & \multirow{2}{*}{ Ethanol } & DMSO & 7.98 & 1.16 \\
& & DMF & 5.87 & 0.83 \\
3. & \multirow{2}{*}{ 2-Propanol } & DMSO & 2.23 & 0.58 \\
& & DMF & 2.05 & 0.52 \\
\hline
\end{tabular}<smiles>COc1c(O)ccc2c1C(=O)c1ccccc1C2=O</smiles>

Fig.7 Intramolecular hydrogen bonding in 1,2-dihydroxyanthraquinone

addition of alcohols whereas in second reduction potential the peak potential shifts towards less negative (positive) side which means that strong hydrogen bond is formed with the added alcohols.
From the observations (as given in the table), it is evident that $\mathrm{MeOH}$ has the highest values of $m$ and $k_{\text {eq }}^{(2)}$ and $\mathrm{PrOH}$ has the least value, this because $\mathrm{PrOH}$ has more bulky structure as compared with $\mathrm{MeOH}$. The values of $m$ and $k_{\text {eq }}^{(2)}$ are not very large as compared to other quinones this may be because of the intra-molecular hydrogen bonding in 1,2-dihydroxyanthraquinone (see Fig. 7) [39].

\subsection{CV of 1,2-dihydroxyanthraquinone in the presence of weak acids: effect of protonation}

Upon addition of weak acid (acetic acid and ascorbic acid) to 1,2-dihydroxyanthraquinone, a quite different behaviour were observed in the redox behaviour of 1,2-dihydroxyanthraquinone (Fig. 8). In the absence of acids, two reversible redox cathodic and anodic peaks were observed because of the formation of anion radical and dianion. However, after addition of weak acid, the second peak (i.e. IIc and Ila) were completely vanishes. Furthermore, a small and continuous positive shift were also recorded in the first cathodic peak (Ic) because of the protonation of weak acids as given in Eqs. (9-11). Peak current also increases at $0.69 \mathrm{~V}$, this is because the protonated semi-quinone reduces immediately [39].

$\mathrm{AQ}+\mathrm{e}^{-} \rightleftharpoons \mathrm{AQ}^{-}$

$\mathrm{AQ}^{--}+\mathrm{HA} \rightleftharpoons \mathrm{AQH}^{-}+\mathrm{A}^{-}$

$\mathrm{AQH}^{-}+\mathrm{e}^{-} \rightleftharpoons \mathrm{QH}^{-}$ 

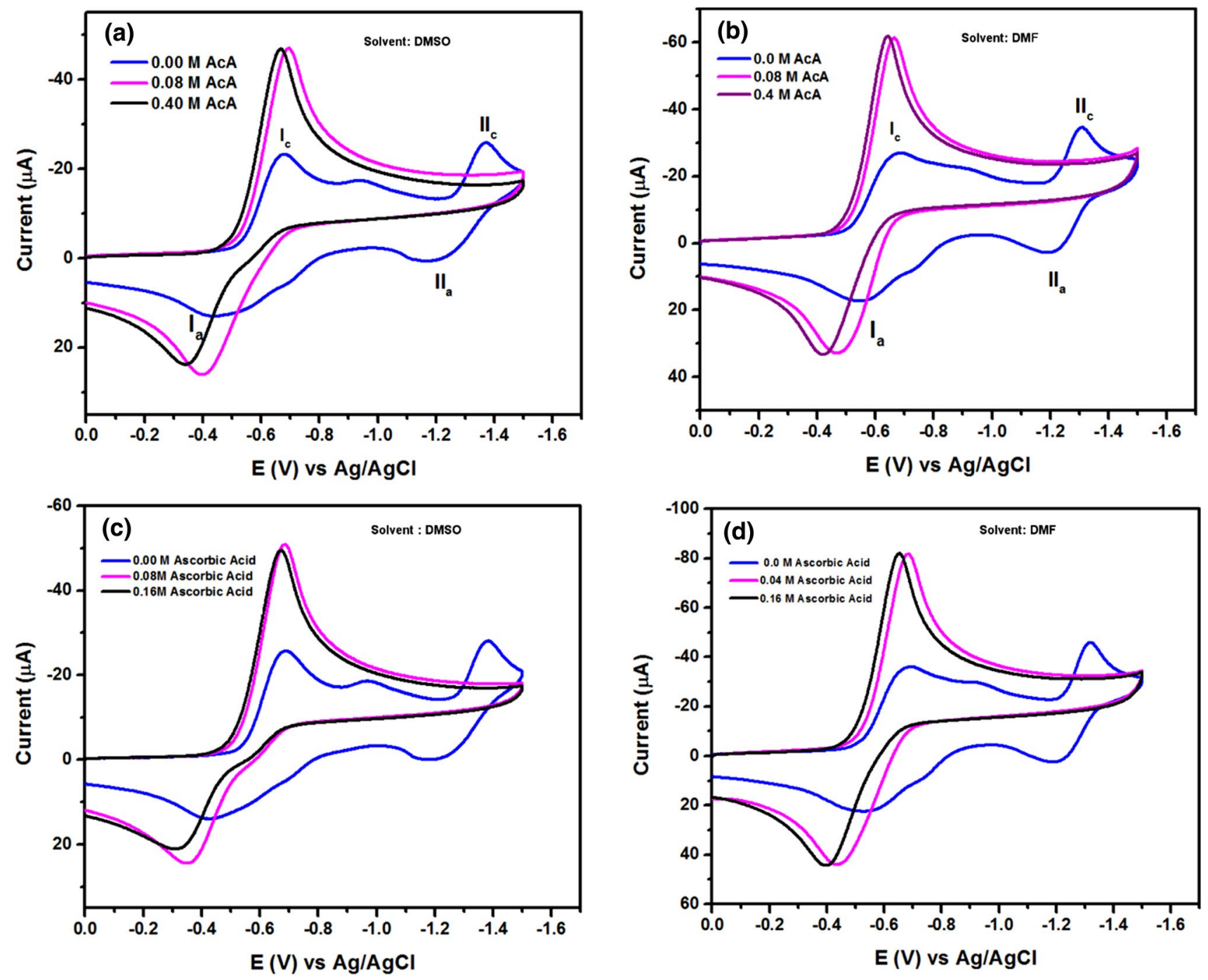

Fig. $8 \mathrm{CV}$ of 1,2-dihydroxyanthraquinone in $\mathrm{LiClO}_{4}$ with different concentration of acetic acid (a, b) and ascorbic acid (c, d) in DMSO and DMF

\subsection{Square wave voltammetry (SWV) study}

The result obtained through cyclic voltammetry was further confirmed through square wave voltammetry. Square wave voltamograms of $3 \mathrm{mM}$ 1,2-dihydroxyanthraquinone in $0.1 \mathrm{M} \mathrm{LiClO}_{4}$ solutions were recorded at a frequency of $50 \mathrm{~Hz}$. No peak was observed in pure media under the argon atmosphere in the absence of 1,2-dihydroxyanthraquinone. With addition of 1,2-dihydroxyanthraquinone results two cathodic peaks at a potential of $-0.64 \mathrm{~V}$ and $-1.32 \mathrm{~V}$ (Fig. 9). As mentioned previously, the two cathodic peaks are because of the formation of anion radical and dianion, the peak potentials of 1,2-dihydroxyanthraquinone is same in both the solvents but peak current in DMF is greater than that of in DMSO. A small peak at a potential of $0.94 \mathrm{~V}$ which is more pronounced in DMSO as compared with DMF represents the hydrogen-bonding intermediate.

\subsubsection{Effect of alcohols (hydrogen bonding agents)}

SWV study Effect of alcohols on the square wave voltammograms of 1,2-dihydroxyanthraquinone in DMSO and DMF is shown in Fig. 10. Various concentration of 

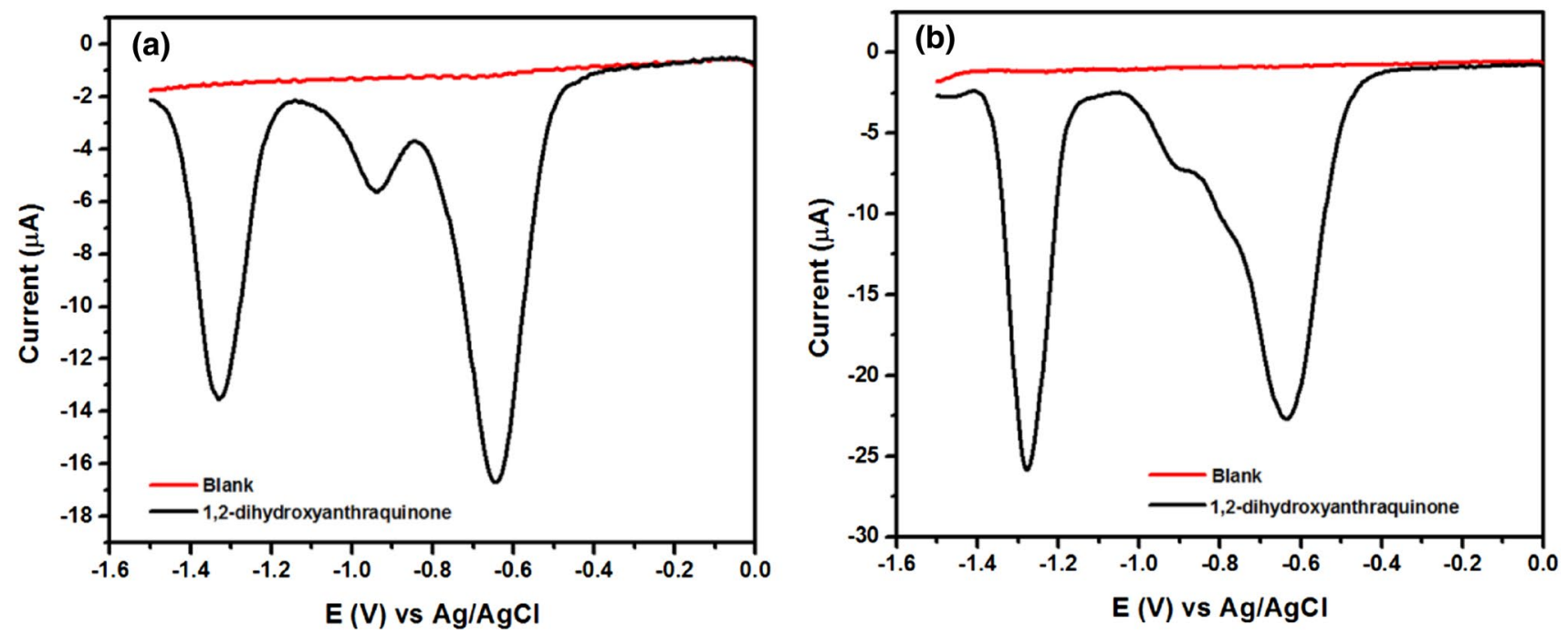

Fig. 9 Square wave voltammogram of $3 \mathrm{mM} \mathrm{1,2-dihydroxyanthraquinone} \mathrm{in} \mathrm{the} \mathrm{presence} \mathrm{of} \mathrm{supporting} \mathrm{electrolyte} 0.1 \mathrm{M} \mathrm{LiClO}_{4}$ in aprotic solvents $\mathbf{a}$ DMSO and $\mathbf{b}$ DMF

methanol was added to the solution of 1,2-dihydroxyanthraquinone which shifted second peak (IIc) towards less negative potential hence confirming the result obtained through cyclic voltammetry for the formation of hydrogen bonding of dianion with alcohols. In case of methanol, the peak current of second peak in DMSO in less than the first peak whereas in DMF the second peak current is greater than the first peak. Addition of ethanol also shifts the peak potential towards less negative side just like methanol, however, the shift due to the addition of ethanol is less than that of methanol which may due to the bulky nature of ethanol. Comparatively, the shift in peak potential with the addition of propanol were much lesser than methanol and ethanol. This is due to bulky $-\mathrm{CH}_{3}$ group present in propanol which hindered hydrogen bond formation.

\subsubsection{Effect of acids through SWV techniques}

Square wave voltammogram of 1,2-dihydroxyanthraquinone in the presence and absence of weak acids are shown in Fig. 11. Here the second peak disappears with the addition of weak acids. The peak current of the first wave also increased due to the abrupt reduction of protonated semiquinone. Further addition of weak acids results a small and continuous shift in peak potential due to the strong hydrogen bonding effect of these weak acid.

\section{Conclusions}

In this study, electrochemical behaviour of 1,2-dihydroxyanthraquinone in the presence of hydrogen bonding and protonating agent was investigated. The compound 1,2-dihydroxyanthraquinone in aprotic solvents showed two well separated oxidation and reduction peaks. The first reduction peak is reversible and the second is quasi-reversible. It was found that 1,2-dihydroxyanthraquinone undergo two electron reduction one after another first form anion radical and then dianion is formed in both the solvents. Furthermore, addition of methanol, ethanol and propanol results in positive shift in the second redox wave of the quinone whereas no change in the first peak. The shift in second peak was attributed to hydrogen bonding between the dianion of quinone with the added alcohol. This shows that the alcohol forms hydrogen bond with the dianion of 1,2-dihydroxyanthraquinone in both solvents DMSO and DMF. Addition of acids i.e. acetic acid and ascorbic acid results in the disappearance of both peaks and a new peak is observed, this is because the acids react immediately with the protonated semi-quinone resulting in hindering the dianion formation. 

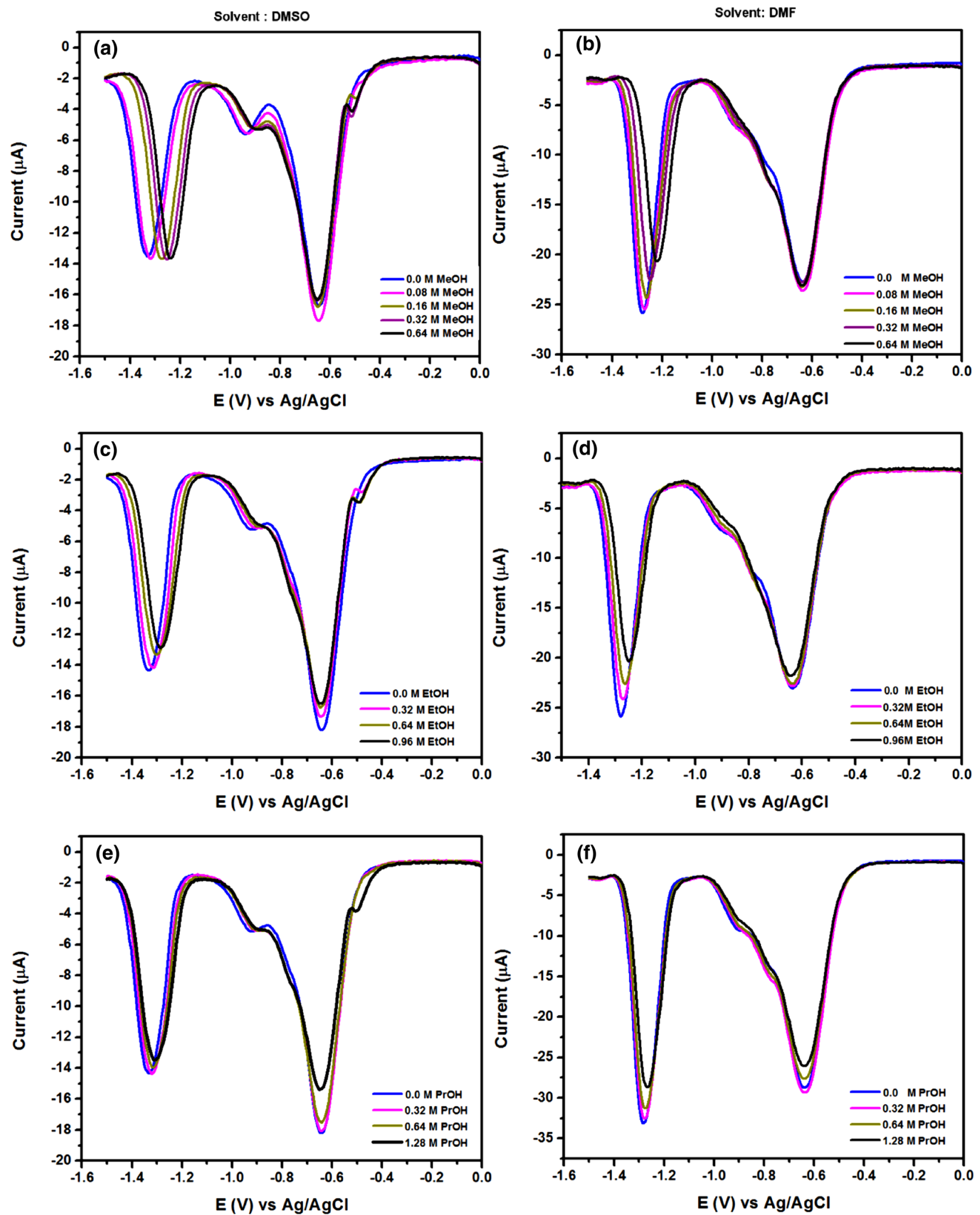

Fig. 10 Square wave voltammograms of 1,2-dihydroxyanthraquinone with different concentration of hydrogen bonding agents-alcohols in $0.1 \mathrm{M} \mathrm{LiClO}_{4}$ in DMSO $(\mathbf{a}, \mathbf{c}, \mathbf{e})$ and DMF $(\mathbf{b}, \mathbf{d}, \mathbf{f})$ 

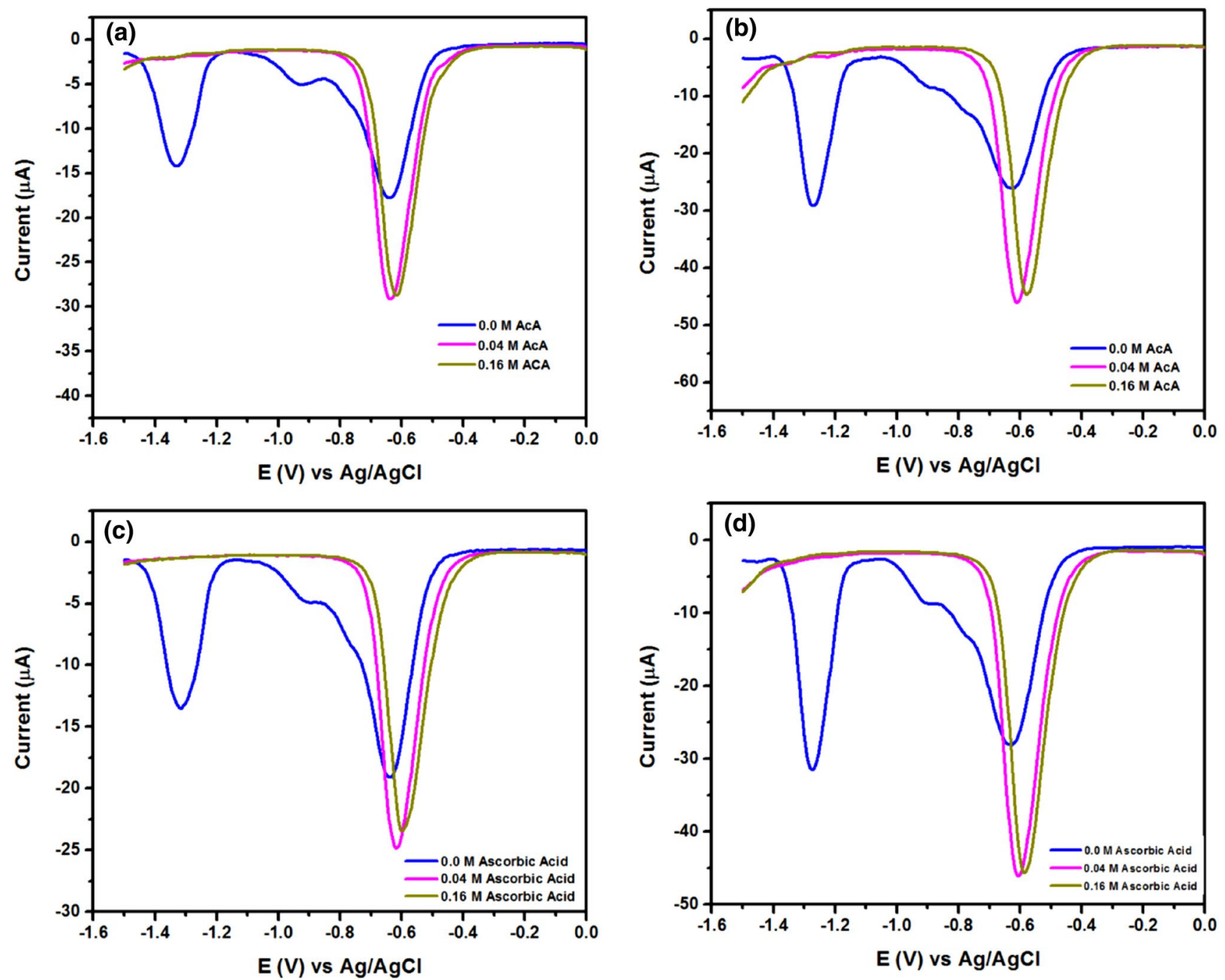

Fig. 11 Square wave voltammetry of 1,2-dihydroxyanthraquinone with different concentration of Acetic Acid and Ascorbic acid in in the presence of supporting electrolyte $0.1 \mathrm{M} \mathrm{LiClO}_{4}$ in DMSO $(\mathbf{a}, \mathbf{c})$ and DMF $(\mathbf{c}, \mathbf{d})$

\section{Compliance with ethical standards}

Conflict of interest The authors declare that they have no conflict of interest.

\section{References}

1. Wilmot CM, Davidson VL (2009) Uncovering novel biochemistry in the mechanism of tryptophan tryptophylquinone cofactor biosynthesis. Curr Opin Chem Biol 13:462-467

2. Setaluri V (2015) Autophagy as a melanocytic self-defense mechanism. J Invest Dermatol 135:1215-1217. https://doi. org/10.1038/jid.2015.19

3. Kato Y, Suga N (2018) Covalent adduction of endogenous and food-derived quinones to a protein: its biological significance. J Clin Biochem Nutr 62:213-220. https://doi.org/10.3164/ jcbn.18-26
4. Ferraz PAL, De Abreu FC, Pinto AV et al (2001) Electrochemical aspects of the reduction of biologically active 2-hydroxy-3alkyl-1, 4-naphthoquinones. J Electroanal Chem 507:275-286. https://doi.org/10.1016/S0022-0728(01)00439-9

5. Rishavy MA, Pudota BN, Hallgren KW et al (2004) A new model for vitamin K-dependent carboxylation: the catalytic base that deprotonates vitamin $\mathrm{K}$ hydroquinone is not Cys but an activated amine. Proc Natl Acad Sci U S A 101:13732-13737. https ://doi.org/10.1073/pnas.0404989101

6. Guin PS, Das S, Mandal PC (2011) Electrochemical reduction of quinones in different media: a review. Int J Electrochem 2011:1-22. https://doi.org/10.4061/2011/816202

7. Sévin DC, Sauer U (2014) Ubiquinone accumulation improves osmotic-stress tolerance in Escherichia coli. Nat Chem Biol 10:266-272. https://doi.org/10.1038/nchembio.1437

8. Block A, Widhalm JR, Fatihi A et al (2014) The origin and biosynthesis of the benzenoid moiety of ubiquinone (coenzyme $Q$ ) in Arabidopsis. Plant Cell 26:1938-1948. https://doi.org/10.1105/ tpc.114.125807 
9. Redfearn ER (1967) Mode of action of ubiquinones (coenzymes Q) in electron transport systems. Vitam Horm 24:465-488. https ://doi.org/10.1016/S0083-6729(08)60217-4

10. Kim JH, Lee M, Park CB (2014) Polydopamine as a biomimetic electron gate for artificial photosynthesis. Angew Chem-Int Ed 53:6364-6368. https://doi.org/10.1002/anie.201402608

11. Guarracino F, Cabrini L, Baldassarri R et al (2011) Noninvasive ventilation for awake percutaneous aortic valve implantation in high-risk respiratory patients: a case series. J Cardiothorac Vasc Anesth 25:1109-1112

12. Hertle AP, Blunder T, Wunder T et al (2013) PGRL1 is the elusive ferredoxin-plastoquinone reductase in photosynthetic cyclic electron flow. Mol Cell 49:511-523. https://doi.org/10.1016/j. molcel.2012.11.030

13. Yusuf MA, Kumar D, Rajwanshi R et al (2010) Overexpression of $\gamma$-tocopherol methyl transferase gene in transgenic Brassica juncea plants alleviates abiotic stress: physiological and chlorophyll a fluorescence measurements. Biochim Biophys Acta-Bioenergy 1797:1428-1438. https://doi.org/10.1016/j. bbabio.2010.02.002

14. Madeo J, Zubair A, Marianne F (2013) A review on the role of quinones in renal disorders. Springerplus 2:1-8

15. Monks TJ, Jones DC (2002) The metabolism and toxicity of quinones, quinonimines, quinone methides, and quinone-thioethers. Curr Drug Metab 3:425-438. https://doi. org/10.2174/1389200023337388

16. Robert P, Cohen GM, Ross VD (1992) CONTEMPORARY ISSUES IN TOXICOLOGY Quinone chemistry and toxicity. Biochemistry $16: 2-16$

17. Huang Q, Lu G, Shen HM et al (2007) Anti-cancer properties of anthraquinones from rhubarb. Med Res Rev 27:609-630. https ://doi.org/10.1002/med.20094

18. Asche C (2005) Antitumour quinones. Mini Rev Med Chem 5:449-467. https://doi.org/10.2174/1389557053765556

19. Prescott $B$ (1969) Potential antimalarial agents. Derivatives of 2-chloro-1,4-naphthoquinone. J Med Chem 12:181-182. https ://doi.org/10.1021/jm00301a053

20. Silver RF, Holmes HL (1968) Synthesis of some 1,4-naphthoquinones and reactions relating to their use in the study of bacterial growth inhibition. Can J Chem 46:1859-1864

21. Carter-cooper BA, Fletcher S, Ferraris D et al (2017) Synthesis, characterization and antineoplastic activity of bis-aziridinyl dimeric naphthoquinone-a novel class of compounds with potent activity against acute myeloid leukemia cells. Bioorganic Med Chem Lett 27:6-10

22. Evans TC, Gavrilovich E, Mihai RC, EL Isbasescu I (2015) (12) Patent application publication (10) Pub. No.: US 2006/0222585 A1 Figure 1. Gridbridge 002:354. https://doi.org/10.1037/t2424 5-000

23. Lee SM, Kwak YS, Lee KH, Kim HT (2015) Control efficacy of fungicides on pepper bacterial wilt. Korean J Pestic Sci 19:323-328

24. Francisco Al, Vargas MD, de Carneiro JWM et al (2008) General method for the high yield preparation of 2-(4-X-phenylene) amine-1,4-naphthoquinones ( $\mathrm{X}=$ ferrocenyl, $\mathrm{OMe}, \mathrm{Me}, \mathrm{I}, \mathrm{Cl}$, and $\mathrm{NO}_{2}$ ) from 2-methoxy-1,4-naphthoquinone and investigation of $\mathrm{H}+$ and $\mathrm{Mg}_{2}+$ catalysts with DFT calculations. J Mol Struct 891:228-232. https://doi.org/10.1016/j.molstruc.2008.03.028

25. Pauling L, Corey RB, Branson HR (1951) The structure of proteins; two hydrogen-bonded helical configurations of the polypeptide chain. Proc Natl Acad Sci U S A 37:205-211. https://doi. org/10.1073/pnas.37.4.205
26. Persch E, Dumele O, Diederich F (2015) Molecular recognition in chemical and biological systems. Angew Chem-Int Ed 54:3290-3327. https://doi.org/10.1002/anie.201408487

27. Migliore A, Polizzi NF, Therien MJ, Beratan DN (2014) The biochemistry and theory of proton coupled electron transfer. ChemRev 114:3381-3465. https://doi.org/10.1021/cr4006654

28. Hammes-Schiffer S (2015) Proton-coupled electron transfer: moving together and charging forward. J Am Chem Soc 137:8860-8871. https://doi.org/10.1021/jacs.5b04087

29. Meyer TJ, Huynh MHV, Thorp HH (2007) The possible role of proton-coupled electron transfer (PCET) in water oxidation by photosystem II. Angew Chem-Int Ed 46:5284-5304

30. Weinberg DR, Gagliardi CJ, Hull JF et al (2012) Proton-coupled electron transfer. Chem Rev 112:4016-4093. https://doi. org/10.1021/cr200177j

31. Bonin J, Costentin C, Robert M, Tard D (2012) Hydrogen-bond relays in concerted proton-electron transfers. Acc Chem Res 45:372-381

32. Gómez M, González FJ, González I (2003) A model for characterization of successive hydrogen bonding interactions with electrochemically generated charged species. The quinone electroreduction in the presence of donor protons. Electroanalysis 15:635-645. https://doi.org/10.1002/elan.200390080

33. Tessensohn ME, Hirao H, Webster RD (2013) Electrochemical properties of phenols and quinones in organic solvents are strongly influenced by hydrogen-bonding with water. J Phys Chem C 117:1081-1090. https://doi.org/10.1021/jp311007m

34. Hui Y, Chng ELK, Chng CYL et al (2009) Hydrogen-bonding interactions between water and the one- and two-electron-reduced forms of vitamin $\mathrm{K} 1$ : applying quinone electrochemistry to determine the moisture content of non-aqueous solvents. J Am Chem Soc 131:1523-1534. https://doi.org/10.1021/ja8080428

35. Martínez-González E, Frontana C (2014) Employment of electrodonating capacity as an index of reactive modulation by substituent effects: application for electron-transfer-controlled hydrogen bonding. J Org Chem 79:1131-1137. https://doi. org/10.1021/jo402565t

36. Mahanthesha KR, Kumara Swamy BE, Chandra U et al (2009) Cyclic voltammetric investigations of alizarin at carbon paste electrode using surfactants. Int J Electrochem Sci 4:1237-1247

37. Trumpower B (1990) The protonmotive Q cycle. J Biol Chem 265:11409-11412. https://doi.org/10.3109/104092394090868 00

38. Tissot $P$, Huissoud A (1996) Proton effects in the electrochemical behaviour of 2-ethyl-9,10-anthraquinone in the medium dimethoxyethane-tetrabutylammonium hydroxide with and without oxygen. Electrochim Acta 41:2451-2456. https://doi. org/10.1016/0013-4686(96)00033-3

39. Gupta N, Linschitz H (1997) Hydrogen-bonding and protonation effects in electrochemistry of quinones in aprotic solvents. J Am Chem Soc 119:6384-6391. https://doi.org/10.1021/ja970028j

40. Ahmed S, Khan AY, Qureshi R, Subhani MS (2007) Hydrogen bonding association in the electroreduced intermediates of benzoquinones and naphthoquinones. Russ J Electrochem 43:811-819. https://doi.org/10.1134/S1023193507070117

41. Mohammad M, Rauf A, Rauf S, Tariq M (2012) The equilibrium and kinetics of intermolecular hydrogen bonding in nitroarene anion radical-alcohol system: 1,3-dinitro-benzene anion radical$\mathrm{R}-\mathrm{OH}\left(\mathrm{R}=\mathrm{CH}_{3}-, \mathrm{C}_{2} \mathrm{H}_{5}-,\left(\mathrm{CH}_{3}\right)_{2} \mathrm{CH}-\right)$. J Phys Org Chem 25:12691274. https://doi.org/10.1002/poc.3005 
Publisher's Note Springer Nature remains neutral with regard to jurisdictional claims in published maps and institutional affiliations. 